\title{
PLASMA CONCENTRATIONS OF VASCULAR ENDOTHELIAL GROWTH FACTOR AND BASIC FIBROBLAST GROWTH FACTOR IN LYMPHOPROLIFERATIVE DISORDERS
}

\author{
Lukáš Smolej ${ }^{1}$, Ctirad Andrýśs ${ }^{2}$, Vladimír Maisnar ${ }^{1}$, Luděk Pour $^{3}$, Jaroslav Malý ${ }^{1}$
}

Charles University in Prague, Faculty of Medicine in Hradec Králové, Czech Republic: $2^{\text {nd }}$ Department of Internal Medicine, Department of Clinical Haematology ${ }^{1}$, Institute of Clinical Immunology and Allergology ${ }^{2}$; Masaryk University, Faculty of Medicine, Brno, Czech Republic: Internal Haematooncology Department ${ }^{3}$

\begin{abstract}
Summary: Angiogenesis plays a major role in the development and progression of haematological malignancies. In our study we measured plasma concentrations of key angiogenic activators vascular endothelial growth factor (VEGF) and basic fibroblast growth factor (bFGF) using comercially available sandwich enzyme-linked immunosorbent assay (ELISA) in 37 patients with lymphoid malignancies and 20 healthy donors. We found a statistically significant increase in bFGF concentrations in patients with B-cell chronic lymphocytic leukemia (B-CLL, $n=18$ ) compared to the control group (median 118.8 vs. $9.3 \mathrm{pg} / \mathrm{ml}, \mathrm{p}<0.001$ ). However, we didn't find any significant difference in VEGF concentrations between B-CLL patients and the control group. There was also no significant increase in bFGF or VEGF in patients with multiple myeloma $(n=7)$ and non-Hodgkin's lymphoma $(n=12)$. Our pilot study shows that measurement of angiogenic activators in plasma is a feasible and reproducible method of angiogenesis assessment. Larger studies are needed for correlation between serum and plasma concentrations and detailed statistical evaluation including the impact on patients' survival.
\end{abstract}

Key words: Angiogenesis; VEGF; bFGF; Leukemia; Lymphoma; Myeloma

Angiogenesis is involved in pathogenesis and progression of haematological malignancies $(3,4,5,6)$. Increased angiogenesis has been found in acute and chronic leukemias, lymphomas, multiple myeloma, myeloproliferative diseases and myelodysplastic syndromes. Recent studies have also correlated increased angiogenesis to inferior clinical outcome and shorter overall survival (4). Determination of angiogenic cytokines in peripheral blood is a common method of angiogenesis assessment $(7,8)$. However, angiogenic fac- tors have been usually measured in serum rather than plasma. Because serum levels of angiogenic factors can be increased by release from platelets during clot formation $(2,9)$, we evaluated feasibility of measuring EDTA plasma concentrations of angiogenic activators - basic fibroblast growth factor (bFGF) and vascular endothelial growth factor (VEGF) using commercially available sandwich enzyme-linked immunosorbent assay (Human bFGF and VEGF Quantikine ELISA kit, R \& D Systems, MN, USA) in 37

Tab. 1: Plasma bFGF and VEGF - descriptive statistics and results of Mann-Whitney U test. B-CLL, B-cell chronic lymphocytic leukemia; NHL, Non-Hodgkin's lymphoma; MM, multiple myeloma; CI, confidence interval; NA, not applicable. All concentrations are in $\mathrm{pg} / \mathrm{ml}$.

\begin{tabular}{|c|c|c|c|c|c|c|c|}
\hline VEGF (ELISA) & $\mathbf{n}$ & Median & Mean & SD & SE & 95\% CI of Mean & p-value vs. controls \\
\hline B-CLL & 18 & 78.8 & 95.5 & 88.5 & 20.9 & $51.5-139.5$ & 0.69 \\
\hline NHL & 12 & 41.9 & 86.9 & 172.0 & 49.7 & $-22.3-196.2$ & 0.3 \\
\hline MM & 7 & 59.7 & 87.8 & 48.0 & 18.1 & $43.4-132.1$ & 0.54 \\
\hline Controls & 20 & 57.5 & 85.2 & 76.1 & 17.0 & $49.6-120.8$ & NA \\
\hline bFGF (ELISA) & $\mathbf{n}$ & Median & Mean & SD & SE & 95\% CI of Mean & p-value vs. controls \\
\hline B-CLL & 18 & 118.8 & 92.7 & 66.5 & 15.7 & $59.7-125.8$ & $<0.001$ \\
\hline NHL & 12 & 10.3 & 16.9 & 21.4 & 6.2 & $3.3-30.5$ & 0.87 \\
\hline MM & 7 & 9.6 & 13.0 & 8.6 & 3.3 & $5.0-21.0$ & 0.63 \\
\hline Controls & 20 & 9.3 & 10.7 & 3.3 & 0.7 & $9.3-12.3$ & NA \\
\hline
\end{tabular}




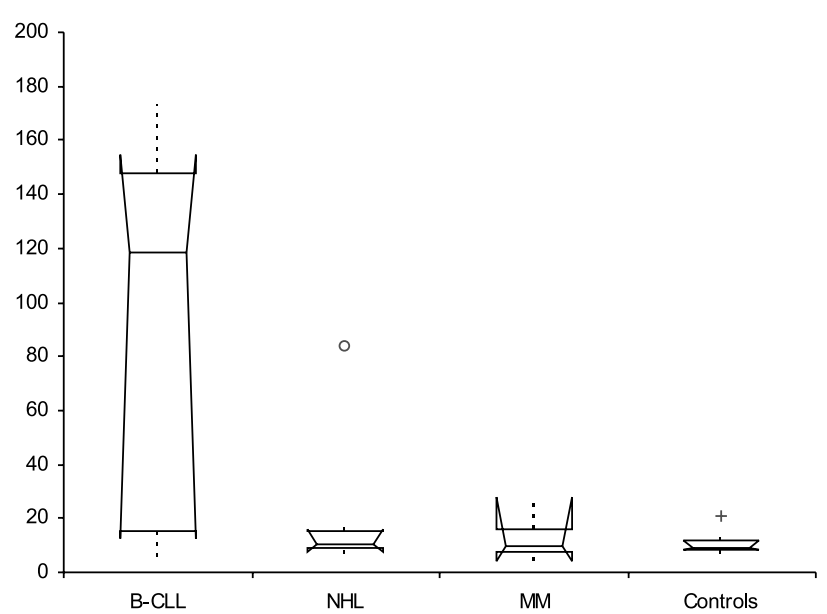

Fig. 1: Box plot comparing bFGF levels in patients with Bcell chronic lymphocytic leukemia, non-Hodgkin's lymphoma, multiple myeloma and controls. Concentrations are in $\mathrm{pg} / \mathrm{ml}$.

patients with chronic lymphoid malignancies. The cohort consisted of patients with B-cell chronic lymphocytic leukemia (B-CLL, $n=18)$, multiple myeloma (MM, $n=7)$ and non-Hodgkin's lymphoma (NHL, $\mathrm{n}=12$ ). Twenty healthy donors were used as the control group. All samples were collected from untreated patients at the time of diagnosis. Median plasma levels of bFGF in B-CLL, NHL and MM patients were $118.8,10.3$ and $9.6 \mathrm{pg} / \mathrm{ml}$. Median levels of VEGF in B-CLL, NHL and MM were 78.8, 41.9 and 59.7 $\mathrm{pg} / \mathrm{ml}$. Median plasma levels of bFGF and VEGF in control group were 9.3 and $57.5 \mathrm{pg} / \mathrm{ml}$ (Table 1). Plasma levels of bFGF in chronic lymphocytic leukemia were significantly higher in comparison to control group ( $\mathrm{p}<0.001$, Fig. 1). The differences in plasma concentrations of bFGF in multiple myeloma and non-Hodgkin's lymphoma as well as VEGF levels in all three diseases compared to control group did not reach statistical significance. Our pilot study shows that ELISA measurement of EDTA plasma levels of angiogenic factors is a feasible and reproducible method of angiogenesis assessment. Results concerning significantly increased bFGF in B-CLL are similar to work of Aguayo and coworkers (1). It is necessary to confirm these observations by a larger study which will enable us to compare serum and plasma concentration of angiogenic factors and to correlate the data with patients' clinical outcome. Nevertheless, the preliminary results are promising and warrant further investigations.

\section{Acknowledgments}

We would like to thank Oldřich Široký, M.D., David Belada, M.D., Pavel Žák, M.D., Ph.D., Jaroslava Voglová, M.D., Alice Sýkorová, M.D., and Milan Bláha, M.D., Ph.D. for their excellent cooperation. This work was supported in part by grants NR/8076 - 3 and NR/8373 - 3 from Ministry of Health of Czech Republic.

\section{References}

1. Aguayo A, Kantarjian H, Manshouri $\mathrm{T}$ et al. Angiogenesis in acute and chronic leukemias and myelodysplastic syndromes. Blood 2000; 96(6):2240-5.

2. George ML, Eccles SA, Tutton MG et al. Correlation of plasma and serum vascular endothelial growth factor levels with platelet count in colorectal cancer: clinical evidence of platelet scavenging? Clin Cancer Res 2000;6(8):3147-52.

3. Kay NE, Bone ND, Tschumper RC et al. B-CLL cells are capable of synthesis and secretion of both pro- and anti-angiogenic molecules. Leukemia 2002;16(5): 911-9.

4. Moehler TM, Ho AD, Goldschmidt $\mathrm{H}$ et al. Angiogenesis in hematologic malignancies. Crit Rev Oncol Hematol 2003;45(3):227-44.

5. Pour L, Hájek R, Büchler T et al. Angiogenesis and antiangiogenic therapy in tumors. Vnitř Lék 2004;12:930-8.

6. Ribatti D, Vacca A, Dammacco F et al. Angiogenesis and anti-angiogenesis in hematological malignancies. J Hematother Stem Cell Res 2003;12(1):11-22.

7. Smolej L. Angiogenesis as a diagnostic and therapeutic target in hematological malignancies. Pracovni dny SZP 2004, Sedmihorky, Book of abstracts, 56-9.

8. Smolej L. Markers of Angiogenesis in Hematological Malignancies. $1^{\text {st }}$ Morphological Postgraduate Workshop, Hradec Králové, 15.2.2005, Book of abstracts, 35 .

9. Webb NJ, Bottomley MJ, Watson CJ et al. Vascular endothelial growth factor (VEGF) is released from platelets during blood clotting: implications for measurement of circulating VEGF levels in clinical disease. Clin Sci (Lond) 1998;94(4):395-404.

Submitted December 2004

Accepted March 2005.

MUDr. Lukáš Smolej,

Charles University in Prague, Faculty of Medicine in Hradec Králové, $2^{\text {nd }}$ Department of Internal Medicine, Department of Clinical Haematology, Sokolská 581, 50005 Hradec Králové, Czech Republic. e-mail: smolej@seznam.cz 